\title{
DESIGN OF LEAN MANUFACTURING-BASED STRATEGIES TO IMPROVE THE PRODUCTION PROCESS OF A METALWORKING COMPANY
}

\author{
Vanessa Valle Mercado; Dayana Benitez Acosta; Dionicio Neira \\ Rodado; Juan Cabarcas Reyes; Aurora Piñeres Castillo; Guilherme \\ Luz Tortorella
}

\begin{abstract}
The objective of this research is to design strategies based on lean manufacturing principles in order to improve the efficiency of the production process of a metalworking company. Lean manufacturing is a continuous improvement philosophy that aims to eliminate or reduce, through different tools, all types of waste found in a production process. During the project, a detailed analysis of the production processes was carried out; with operations diagrams, Pareto charts, Ishikawa diagrams, VSM, among others. With these, it was possible to determine the different problems present in anchor rods and clamps production lines. According to the project's progress, each of the improvement strategies was developed, proving its functionality and utility for productivity and cost reduction. Finally, the waste reductions generated by each strategy were calculated, and then the benefits and the investment required for the implementation of the strategies, justified by the cost-benefit analysis.
\end{abstract}

\section{Keyword}

Manufacturing; Metalworking company; Lean Manufacturing; Continuous improvement; 